\title{
Globalization and responsibility for human rights
}

\section{De Smet A, Dirix J, Diependaele L, Sterckx S}

\section{Introduction}

In 1948, the Universal Declaration of Human Rights (UDHR) was adopted by the United Nations General Assembly. ${ }^{1}$ Despite important progress made over the last 66 years, many of these human rights still remain unfulfilled. ${ }^{2}$ In 2010, 2.4 billion people were living under the $\$ 2$ poverty line, 1.2 billion of whom had to live with even less than $\$ 1.25$ per day (World Bank 2013a). ${ }^{3}$ In 2010-2012, about 870 million people (or 1 in 8) were undernourished and an estimated 11 percent had no access to adequate drinking-water (FAO 2013: 67, 80). The human right to basic education ${ }^{4}$ is still not met for 57 million children and child mortality (6.9 million in 2011) remains high (UN 2013: 4-5). Moreover, diarrhoea kills around 760,000 children under five each year, although this figure could be significantly reduced through the provision of safe drinking-water and adequate sanitation and hygiene (WHO 2013). While future people are likely to suffer most of its adverse effects, anthropogenic climate change already impacts human life and worsens this situation, since it results in an increased frequency and intensity of heatwaves, floods, storms, fires and droughts (Confalonieri et al. 2007: 373). Indeed, anthropogenic climate change 'violates the human rights to life, physical security, subsistence and health' (Caney 2010; Bell 2011: 100). The fact that developing countries are likely to bear $75 \%$ of the costs of damages resulting from climate change (Hoornweg et al. 2010: 4) makes this situation even more problematic. 
Our framework for this paper is the 'responsibilities approach' to human rights, as developed by Kuper et al. (2005: ix-xxii). Proponents of this approach focus on the counterpart obligations ${ }^{5}$ that arise from human rights. They stress that if we fail to identify the agents that bear those obligations, we are at risk of emptying the human rights discourse of any meaningful content. To avoid this risk, we need a sound account for the allocation of responsibilities within our globalized world. The responsibilities approach to human rights is devoted to this major task:

... the responsibilities approach to human rights - where we demand, in every context, to know "who must do what for whom?" - provides the conceptual resources to move beyond conventional pieties and statist strictures. It provides a much-needed bridge that at once strengthens the discourses of rights and accountability and links them to one another: Responsibility becomes the middle term that allows us to delineate justifiable and feasible rights-claims and to identify and hold to account agents who can and should deliver on those rights. (Kuper et al. 2005: xxii)

Taking this approach as a starting point, we wish to examine which rights-claims are justified and who then bears the responsibility to fulfill these claims. Before we can answer this question, we need to make some observations on the nature of human rights.

Traditionally, a distinction is made between negative rights (understood as rights to noninterference) and positive rights (conceived of as rights to assistance). In the same way, a distinction is made between negative duties of noninterference and positive duties of assistance (Cruft 2005: 29-30). 
Although the relevance of this distinction has been criticized (Shue 1980), we agree with Samuel Scheffler (2001: 39) that it remains one of the important hallmarks of our common sense conception of individual responsibility. Indeed, if we do not want to jeopardize the feasibility of our effort to ground human rights and allocate the corresponding obligations, we should not neglect the common sense view of responsibility. As explained by David Miller:

From the agent's perspective there may be a difference between the stringency of the duty to refrain from causing harm and the duty to act beneficially, corresponding to the familiar (though much debated) distinction in moral philosophy between acts and omissions. Furthermore, whereas negative duties clearly fall on all agents, whether individual or collective, in the case of positive duties there is a substantive question about whose responsibility it is to provide the resources needed to secure basic rights, whenever there are many agents each of whom could potentially discharge the duty in question. (Miller 2005: 47)

In this paper we therefore give priority to negative duties, precisely because this is a minimalist normative position which is widely acceptable. For example, the distinction between causing poverty and merely failing to reduce it, is morally significant in the common sense view of responsibility: 'individuals have a special responsibility for what they themselves do, as opposed to what they merely fail to prevent' (Scheffler 1995: 223). When we apply this distinction to the human rights approach, it becomes clear that our first and foremost duty is to avoid the active violation of negative human rights. Following Thomas Pogge (2008: 25), a prominent human rights theorist, we will take this conception as our 
baseline for determining harm and injustice. We take the claim that if one violates people's human rights, one is harming those people, to be uncontroversial.

In the next section, we will examine how negative and positive rights fit in with the common sense distinction between general and special obligations. Our focus in section 3 will be on exactly what constitutes a reason to value relationships. In section 4, we will argue for the need to consider harm when developing an account of responsibility for human rights in a globalized world. We will focus on the global economic order and on climate change and examine whether these aspects of globalization provide us with new reasons to value our relationships with distant others. In the final section, we will consider whether Christian Barry's 'vulnerability presumption principle' (Barry 2005a: 221) can help us in answering these questions.

\section{General and special obligations}

How is the distinction between negative and positive duties reflected in our moral outlook? To begin with, in common sense morality we distinguish between general and special obligations. The former are owed to everyone equally, on the basis of our common humanity. Human rights seem to provide the most evident basis for these general obligations. As for the negative duties entailed by human rights, i.e. the rights to noninterference, there seems to be no problem. For example, it seems inconceivable to deny someone the right not to be killed, except in very extraordinary circumstances such as self-defence.

Positive duties (i.e. duties of assistance), however, are much more controversial. Some commentators, for example Shue (1980), argue that we have a general obligation to fulfill the 
subsistence rights of distant others, even if this implies positive duties. According to libertarians, however, we bear no general positive obligations, as long as we did not previously make any promises or violate any negative duties (Narveson 1988: 59-60). Pogge is said to side with libertarians on the question of normative principle, for he does not argue that we have positive duties yet he tries to challenge the libertarians' factual claim that the affluent do not harm the world's poor by causing their poverty (Patten 2005: 20). Rather than explicitly endorsing a libertarian view, he takes up an ecumenical strategy in an attempt to convince proponents of all important schools of thought (Pogge 2005a: 95). By avoiding claims about positive duties, he seems to want to make clear that his argument does not depend on positive duties (Ibid.: 93). We will return to this issue later.

As noted earlier, our general obligations are owed to everyone equally, on the basis of our common humanity, yet they do not seem to imply respect for positive human rights. We all bear the general obligation not to interfere negatively with another person. However, our general positive duties of assistance are less stringent and more problematic, from a motivational, and also - and more importantly - from certain theoretical points of view. Moreover, as noted earlier, we face the difficulty of assessing who should bear those responsibilities, if we do not want to make the human rights discourse void of meaning. This difficulty is known as the 'allocation problem'. We shall come back to it later.

In contrast to general obligations, special obligations are owed only to some specific subset of persons with whom we have a special relationship, i.e. we do not bear them for everyone equally. We feel we owe more to our brother, a friend, or perhaps a fellow countryman, than to a distant stranger. In addition to negative duties of noninterference towards them, we also feel that we owe them duties of assistance. In other words, special 
positive obligations are less controversial than general positive obligations. No mother would refuse to share her food with her child, claiming that this would impose an unjustified infringement of her freedom, for example. Few people would deny the existence of such special positive obligations.

Admittedly, general and special obligations often coexist without problem, but sometimes they do conflict. When this happens, should we be allowed to give priority to our special positive obligations and neglect our general ones? For example, should we be allowed to buy a birthday present for our son while other people are living in severe poverty? What exactly constitutes a special relationship and bestows compelling force to preference it? Two types of answers have been given to this question: 'reductionist' and 'non-reductionist' answers (Scheffler 2001: 98).

Reductionists suppose that special obligations arise out of specific interactions that occur in the context of our relationships, such as promises, mutual interdependences or a notion of reciprocity. For example, we have a duty to take care of our elderly parents because they nurtured us when we were young. Non-reductionists, in contrast, believe this is 'one thought too many' (Williams 1981: 18). For them, the mere fact that we value a relationship with someone gives rise to a special obligation towards this person. The relationship itself, not some preceding interaction, is the source of the special responsibility we bear (Scheffler 2001: 100-104).

Does non-reductionism imply that every relationship that we value is equally morally significant? According to Wellman (2000: 552-554), the non-reductionist approach is vulnerable to objections when it tries to answer this question. If non-reductionists want to 
maintain that our intuitions about relations are what really matters, they cannot denounce racism or sexism. Some people place great value on their relationships with people belonging to the same group, which would establish special responsibilities towards that subset of persons. Yet Van der Vossen (2011: 489) rightly raises the following question:

Can we really accept that members of morally reprehensible communities may bring into being moral obligations to support and maintain those communities and practices simply by having certain attitudes? Surely it is not that easy to ordain unjust practices with moral quality.

Non-reductionists can try to avoid this conclusion by showing why the relationship with our compatriots may imply a special responsibility and our relationship with people of the same race or sex may not. Yet, in doing so they would have to point to other grounds than the relationship itself to explain this difference. Consequently, they would cease to defend a nonreductionist account. In sum, special responsibilities based on special relationships that one should not value cannot be refuted on purely non-reductionist grounds.

Non-reductionism also seems to face another problem. People do not only value relations they should not value (e.g. racism), but also do not value relations they should value. Some liberals reject every responsibility that one has not voluntary accepted (the voluntarist objection), but can consent really be that important? If a mother does not think she has a special relationship with her child, does this imply that she bears no special responsibility for the child? Do we only have responsibilities for those we already have accepted responsibility for? Alternatively put, simply because we do not believe that our relation with distant 
strangers is special, does this mean that our failure to alleviate their severe poverty is acceptable?

\section{A relationship one has reason to value}

In his book Boundaries and Allegiances, Samuel Scheffler focuses on the responsibilities we bear as individuals in a globalized world. He believes that the changing circumstances of the modern world have resulted in a growing uncertainty about exactly what those responsibilities are. He holds that the restrictions imposed on individual responsibility, on the basis of a conception of human social relations as 'consisting primarily in small-scale interactions, with clearly demarcated lines of causation, among independent individual agents', have become questionable (Scheffler 2001: 39-40). He therefore claims that the restrictive conception of individual responsibility, embodied in common sense moral thought, is outdated.

Indeed, our special obligations do increasingly seem to conflict with our general obligations. As explained in the previous section, our negative duties regarding human rights are equally stringent on both accounts. However, our positive special obligations towards our friends and families seem to take precedence over our positive general obligations to satisfy the human rights of distant others. We feel ourselves torn between the values of loyalty and equality, while most of us cherish both (Scheffler 2001: 79). Scheffler tries to reduce this tension without giving dominance to either one of these values. Essential in this attempt is his non-reductionist defence of special responsibilities: 
Among the things that we value are our relations with each other. But to value one's relationship with another person is to see it as a source of reasons for action of a distinctive kind. It is, in effect, to see oneself as having special responsibilities to the person with whom one has the relationship. Thus, in so far as we have good reasons to value our interpersonal relations, we have good reasons to see ourselves as having special responsibilities. (Scheffler 2001: 103)

Important here is that Scheffler considers these relationships to generate responsibilities irrespective of whether or not these relationships are actually valued. He does not deny the importance of choice or consent in determining which relationships matter, but refuses to ground all responsibility in our own decisions, 'for the relationships that generate responsibilities for an individual are those relationships that the individual has reason to value' (Scheffler 2001: 107). An important fact of moral duties thus seems to be that we are bound by them, 'regardless of whether we happen to believe that we are or want to be' (Moellendorf 2002: 35). Nagel (2005: 121) describes a similar idea in his characterization of the political conception of justice:

..., though the obligations of justice arise as a result of a special relation, there is no obligation to enter into that relation with those to whom we do not yet have it, thereby acquiring those obligations toward them. If we find ourselves in such a relation, then we must accept the obligations, ...

In this way, Scheffler tries to refute the voluntarist objection, raised by some liberals, in a non-reductionist way. The question as to whether he succeeds in this effort is difficult to 
answer, since Scheffler does not specify the exact meaning of 'having a reason to value' a relationship. His account appears to resemble Hardimon's principle of reflective acceptability (1994: 348):

To say that a social role is reflectively acceptable is to say that one would accept it upon reflection. Determining whether a given social role is reflectively acceptable involves stepping back from that role in thought and asking whether it is a role people ought to occupy and play. Determining that a given social role is reflectively acceptable involves judging that it is (in some sense) meaningful, rational, or good.

Scheffler's account resembles Hardimon's, since both seem to imply that special responsibilities can be generated - upon reflection - even without an actual consent. However, their accounts diverge in that Hardimon specifies which properties establish a role (or relationship) as reflectively acceptable, viz. meaningful, rational, or good, whereas Scheffler does not aim to develop a detailed account of the responsibilities one might have.

Barry and Lawford-Smith (2012) outline a number of reasons that may generate special obligations and responsibilities, apart from the special relationships that we voluntarily enter into through contracts or promises. They mention special obligations we might have towards citizens of our (ex-) colonies (Ypi et al. 2009) and responsibilities we bear for people who are vulnerable to our actions (Goodin 1985). They also ask whether we should be held responsible if we benefit from certain injustices distant others experience and in which we have thus become morally complicit (Barry and Lawford-Smith 2012: xiii). 
As far as general obligations are concerned, we have already mentioned our common humanity as a good reason to value our relationship with the rest of mankind. We bear general obligations towards everyone, but, as we have seen, these are commonly held to be limited to negative duties that are derived from human rights, i.e. duties of non-interference. Grounding (enforceable) positive duties on our common humanity seems to be more problematic. Hinsch and Stepanians (2005: 303) explain why:

A human right [for example] not to suffer severe poverty seems to be a special right. In this type of right, all of us are candidates for the corresponding duties, but only some of us are actually bound. Because of the referential opaqueness of the term "some," however, human rights of this kind give rise to what we call "the allocation problem," i.e., the task of identifying the relevant dutybearers and of specifying their concrete obligations. [...] universal complex rights to abstract values against anonymous "somebodies" have at best weak regulative force unless they are supplemented by a determination of their concrete addressees with their specific active duties.

In the following section, we will argue that harm should be used as the criterion when looking for a solution for this allocation problem.

\section{Harm as a good reason to value a relationship}

As mentioned in the introduction, we take the active violation of negative human rights as our baseline for determining harm. We believe that if one violates somebody's human rights, one is, without any doubt, harming that person. In this 
section, we will examine how this conception affects the obligations we bear. Our obligations seem to be more stringent when we stand in some causal relationship to some other(s), including distant others. When we are, in some way, responsible for the situation of others, we are more likely to feel obliged to assist them (Dobson 2003: 171). Christian Barry elaborates on this intuition in his formulation of a "contribution principle'. This principle is based on the aforementioned distinction between doing something and failing to prevent it. He considers the fact that we contributed to something to be 'a normative factor of special significance for determining whether and to what extent [we are] responsible for addressing it' (Barry 2005b: 107). In the context of acute deprivations, he characterizes our responsibilities as especially weighty:

there are strong moral reasons to refrain from contributing to others' acute deprivation regardless of any further connections that we may have to them, so that we cannot easily appeal to considerations of cost to ourselves to excuse our failure to act on them. (Barry 2005a: 212)

Referring to Linklater, Dobson (2003: 28) also emphasizes the importance of relations of actual harm. He describes harm as a source of political obligation and considers avoiding harm, or compensating for it, to be an obligation of justice rather than charity. He also argues that these obligations of justice are especially binding. Harming someone thus seems to be a very strong reason to value a relationship. ${ }^{6}$ We are in a special relationship with the people whose human rights we violate and we bear responsibility towards them, regardless of whether or not we actually value this relation. Even though many will fail to adopt this responsibility voluntarily, this does not exonerate us from it. As Nagel has put it: 'to treat 
someone else horribly puts you in a special relation to him' (Nagel 1972: 137). We cannot simply dismiss our obligations merely because we do not feel (sufficiently) motivated to accept them.

The distinction between 'obligations of charity' and 'obligations of justice' is important here. Pogge illustrates this distinction as follows:

Suppose we discovered people on Venus who are very badly off, and suppose we could help them at little cost to ourselves. If we did nothing, we would surely violate a positive duty of beneficence. But we would not be violating a negative duty of justice, because we would not be contributing to the perpetuation of their misery. (Pogge 2008: 204)

As stated in the introduction to this paper, we hold that a failure to meet our negative duty not to harm generates obligations of justice. This is not to say that avoiding harm constitutes the alpha and omega of justice, but we agree with Pogge that respecting negative human rights is a necessary condition for justice (Pogge 2005b: 76). When we neglect a duty of charity to, say, feed a hungry child, we may be blameworthy for failing this duty, but we are arguably not failing to fulfill a duty of justice. When we are causally responsible for the malnutrition of that child and still fail to feed it, however, we are acting unjustly. Through the process of harming, the general positive duty of charity of feeding the child becomes a special positive duty of justice. This is not merely a question of semantics; it endows the human right to food with more stringency and, thus, hopefully, more motivational power. ${ }^{7}$ 
Through the process of globalization we have become causally interconnected with virtually everyone. As such, this does not constitute a reason to value our relationship with every distant other. However, if we would turn out to be systematically harming others, this would generate a strong reason to value the relationship, namely a reason of justice. Accordingly, the harm we inflict gives rise to a special obligation to a very large subset of persons, with a potentially universal scope.

\subsection{Does our economic interdependence constitute a reason to value relationships?}

Darrel Moellendorf (2002: 30-8) uses the concept of 'global association' as the starting point for his theory of global justice. He argues that duties of justice are special, generated by associational reasons, for example when people are connected through politics or commerce. If the institutions that govern those practices have a substantial impact on the highest order moral interests of people, they give rise to duties of justice on a global scale. To assess this impact, he focuses on people's life prospects and concludes that these differ immensely based on the location of one's birth. We largely agree with Moellendorf's account, but, as noted in the introduction, the benchmark that we propose, following Pogge, is harm through violating human rights.

In World Poverty and Human Rights Pogge argues that we, the global rich, are harming the global poor through the global economic order we uphold. We are not merely failing to fulfill a positive duty of charity or assistance; we actively violate our negative duty not to harm other people. Our economic order foreseeably and avoidably causes human rights deficits and everyone who participates in its creation or imposition consequently harms those affected negatively (Pogge 2008: 25-26). If this is the case, we would have a strong reason to value our 
relationship with the global poor and to shoulder the special responsibilities resulting from that relationship.

Pogge supports his claim by pointing to two privileges that appear to play an important role in the active violation of our negative duty, namely the international borrowing privilege and the international resource privilege. Both rely on the fact that our representatives in international negotiations, our governments and most corporations tend to regard leaders of other countries as legitimate representatives of their people - irrespective of how they came to power, how they exert it, or the extent to which they are supported by their domestic population (Pogge 2008: 118). Let us look at each of these privileges in turn.

The international borrowing privilege focuses on the right that the international community grants to rulers to borrow money. Pogge mentions three important adverse effects of this privilege (Pogge 2008: 120-121). First, it enables rulers to remain in power, since it allows them to borrow much more and more cheaply. They can use this money as they please, which sometimes boils down to paying militias to oppress popular opposition. Second, coup attempts and civil wars become more attractive. Whoever succeeds in a coup gets the borrowing privilege as an important bonus. The third effect regards the situation after a dictatorship has been overthrown. The succeeding government is very likely to be crippled by the huge debts made by the ousted despot and to be incapable of implementing the necessary reforms. As such, the international borrowing privilege continues to harm the people, even after the oppressive regime has been overturned.

The international resource privilege, in turn, not only recognizes the effective control that those in power have over the resources of their country, but also seems to legitimize this 
control (Pogge 2008: 119-120). When a company buys resources from a corrupt despot, it becomes the legitimate owner of those goods, regardless of how the despot came to power or what he does with the money acquired through the sale. As history has repeatedly shown, the resource privilege provides a strong incentive for coup attempts and civil wars in resourcerich countries, which is an aspect of the 'resource curse' (Auty 1993). Similar to the borrowing privilege, the resource privilege financially rewards whoever successfully comes to power and provides them with the means to maintain their position. Therefore, Pogge (2001: 22) concludes that:

the underfulfillment of human rights in the developing countries is not a homegrown problem, but one we greatly contribute to through the policies we pursue and the international order we impose. We have then not merely a positive responsibility with regard to global poverty, like Rawls's 'duty of assistance,' but a negative responsibility to stop imposing the existing global order and to prevent and mitigate the harms it continually causes for the world's poorest populations. Because our responsibility is negative and because so much harm can be prevented at so little cost to ourselves, the reduction of severe global poverty should be our foremost moral priority.

The question arises, however, as to whether we are indeed failing to fulfill a negative duty, or whether, as argued by Patten (2006: 27), Pogge '[stretches] the concept of harm awkwardly to make space for duties of assistance [i.e. positive duties]?' Is the fact that a different economic order, which would cause less suffering, is possible, sufficient to support the claim that, in the current economic order, the affluent are indeed harming the poor? According to some commentators, this conclusion is too strong. 
According to Mathias Risse, we should be reluctant to accept this conclusion in view of the meaning of 'feasible alternatives' (Pogge 2008: 26). Risse (2005a: 371) considers that Pogge mistakenly thinks that feasibility primarily concerns allocating money to developing countries. Risse argues that, in addition to money, institutional improvements are necessary and he points out that there is no consensus or 'royal road' (Kuper 2002: 117) in the social sciences on how to eradicate poverty (Risse 2005a: 373-375). We agree with Risse that the mere allocation of money will not be enough and that institutional improvements are necessary to ensure that the intended changes are sustainable. Paul Collier elaborates this point in The Bottom Billion. Why the Poorest Countries are Failing and What Can Be Done About It. He examines which role aid can play and concludes that aid alone will not solve the problems of the bottom billion, as some thinkers on the left seem to believe. However, against the right, he argues that aid is part of the solution, rather than the problem $(2007: 123,191)$. To reach this solution, complementary institutional changes are needed. Focusing on money alone is no longer a viable option; we need to take the 'institutional turn' (Evans 2005). Collier mentions new trade policies, security strategies, international charters, and changes in the domestic law of rich countries as necessary conditions for effectively benefiting the poor. More specifically, Collier mentions, among other things, the importance of restoring order, maintaining peace and fighting corruption. Furthermore, democracy, budget transparency, and African trade liberalization seem to be crucial instruments for the intended poverty reduction.

Bearing this in mind, we do not agree that Pogge holds that allocating money will in itself eradicate world poverty. Risse unfairly critizes Pogge for not focusing on specific mechanisms through which the global order inflicts poverty on developing countries. At the same time, we would submit that a related question needs to be addressed, namely, which 
conditions must be met before a measure counts as an institutional change? For example, why is the Global Resource Dividend (GRD) that Pogge proposes regarded as 'allocating money' rather than as an institutional reform? Under this scheme, states would be required to share a small part of the value of any resources they decide to use or sell. This payment would be used for the benefit of those who otherwise would be excluded from their proportional share of the world's resources, e.g. the global poor (Pogge 2008: 202). Risse might reply that this proposal is not sufficiently elaborated and that its chance of being successfully implemented is rather slim, because the necessary institutions (e.g. a functioning democracy) are not in place worldwide. This seems to imply that the GRD is indeed best characterized as an institutional reform. Would the Health Impact Fund (HIF), a mechanism designed by Pogge and Hollis (2008) to optimize the development and worldwide distribution of (essential) medicines, count as an institutional change? Pogge and Hollis explicitly acknowledge that this proposal needs to overcome some difficulties, such as the last mile problem, i.e. the challenge of ensuring the accessibility and correct use of these medicines (Pogge \& Hollis 2008: 71-73). Does this problem of implementation really exonerate the current order (and the people that impose it) of all charges of harm regarding access to medicines? As a third example, Pogge's plea for a world order without the international borrowing privilege and international resource privilege clearly illustrates that he does focus on institutional mechanisms and does not think allocating money is the final solution. Thus Risse's criticism seems undeserved.

For Pogge, the measures required for institutional reform constitute duties of justice, whereas Risse believes them to be duties of assistance in institution building. Risse emphasizes that we do not have a well-understood blueprint for eradicating poverty or successful development, which he believes to be necessary. This seems to imply that, for Pogge's claim that upholding the global order is harming the poor to be true, we would need 
to have an agreed and implementable plan of action at our disposal. However, it might be questioned whether such a fixed action plan is really necessary to make the concept of a 'feasible alternative' intelligible. Given the complexity of our modern world, we believe this condition might be too stringent. It seems that every course of action will always have both advocates and opponents. Correspondingly, it seems overly demanding to expect a full-blown plan of implementation for every proposal. We do not deny the importance of a broad consensus or viable implementation measures, yet we consider that Risse's use of the concept 'feasible alternative' is too stringent. John Rawls (1999: 12) has discussed this tension in connection with his concept of a 'realistic utopia':

I recognize that there are questions about how the limits of the practically possible are discerned and what the conditions of our social world in fact are. The problem here is that the limits of the possible are not given by the actual, for we can to a greater or lesser extent change political and social institutions and much else. Hence we have to rely on conjecture and speculation, arguing as best we can that the social world we envision is feasible and might actually exist, if not now then at some future time under happier circumstances.

However, in this respect Pogge and Risse again do not differ as much as one might expect. Risse (2005a: 376) admits that Pogge's claim is not entirely implausible. He concedes that the absence of a blueprint does not give us the right to rest on our laurels:

To be sure, this understanding of feasibility still does lead to an indictment of the global order if a case can indeed be made that not enough effort goes into 
exploring possibilities for and, if appropriate, implementing institutional change.

Yet how do we determine exactly when an alternative has enough support and when the probability of being implemented is high enough for it to count as 'feasible'? How much agreement and information is needed before a relationship of harm is can be said to be present? This is indeed a difficult question to answer. Risse correctly argues that we need a case-specific empirical analysis to discover how we can bring about institutional improvement (2005a: 373). When we take the individual as our ultimate unit of concern (Pogge 1992: 48), the urgency of the task of exploring avenues towards institutional improvement becomes clear. Even in the absence of an easily feasible alternative, it is clear, for example, that the current institutional framework regarding medicines is harming hundreds of thousands of people, as they cannot afford essential medicines because these are patent protected in accordance with the WTO TRIPS agreement (UN 2012). Alternatives, such as the Health Impact Fund, face opposition and will not be implemented without considerable difficulties. However, can this really serve as an excuse for the suffering of so many people under the current regime?

Our responsibility to implement the ultimate blueprint is somewhat meaningless, as such a blueprint clearly does not exist. Our duty to search for institutional improvements, however, remains solidly in place, although substantiating this duty is a difficult task. Which possibilities deserve to be further explored and to what extent? Secondly, which explored proposals are promising enough to be implemented and to what extent? There is no easy answer to these questions. For example, at the moment, the Health Impact Fund arguably does not yet enjoy widespread support and cannot yet be easily implemented. However, a pilot 
field test ${ }^{8}$ might refine the scheme before it is implemented it on a wider scale, and hence might improve the feasibility of the original, more comprehensive proposal. Recently, Janssen Pharmaceutica, part of Johnson \& Johnson, has made a commitment toward a joint HIF pilot involving their new drug against multi-drug-resistant tuberculosis, bedaquiline. Janssen will contribute this drug at zero cost, with the intention of refining the measurement of health gains and the preservation of drug's efficacy. ${ }^{9}$ This initiative does not in itself establish that HIF is a feasible alternative for the status quo. It does, however, show that the possibilities for institutional change have hitherto not been adequately explored.

Risse is right to point out that there are numerous possible ways of improving the situation of the poor through institutional changes (2005a: 375). From this fact he infers that exploring possible institutional changes is a positive duty of assistance. However, since the current regime fails to meet even a minimal standard of human rights (e.g. access to essential medicines), it cannot be just (Pogge 2005b: 56). Searching for feasible alternatives for this unjust situation can no longer be characterized as a duty of assistance: the fact that we impose an institutional order that violates human rights gives rise to a relationship of harm and therefore a negative duty of justice. Only if no human rights were violated, would the duty to search for even better alternatives be a duty of assistance. Since Risse agrees that not enough has been done to explore and, if appropriate, implement institutional changes, and that the global economic order does harm the poor in this sense (2005a: 376), it is puzzling why he insists on calling the rectification of this situation a duty of assistance. We conclude that Risse's argument for doubting Pogge's claim that the global economic order is harming the poor, is unconvincing. 
Robert van der Veen (2005) provides us with a second reason to question Pogge's conclusion. He attempts to rebut the claim that the affluent are harming the poor by pointing out three options we have regarding the current global economic order: we can sustain the status quo; we can improve it to alleviate suffering; or we can worsen it. If we worsen the situation, we are definitely violating our negative duty not to harm others. If we merely sustain the status quo, we are failing our positive duty to improve the situation of the global poor and are thus blameworthy, but not in the same sense as we would be if we had aggravated the situation. The longer we fail to fulfill our positive obligation to improve matters, the stronger its claim on us becomes, but it cannot suddenly switch from a positive to a negative obligation. Our obligation of assistance or charity then admittedly becomes more urgent, but it does not evolve into an obligation of justice.

Thus, although a morally superior global economic order is possible, not improving the status quo does not amount to violating our negative duty not to harm, according to van der Veen. Therefore, he believes that merely sustaining the status quo without reforming global economic institutions is not sufficient to constitute a harm-based reason to value our relationship with the global poor and to bear special responsibilities for them. This argumentation needs to be elaborated further. After all, it is not self-evident why we should take the current global economic order as the significant benchmark for harm, i.e. the harmneutral position.

Risse (2005b) distinguishes three different possibilities. The first alternative benchmark is to compare the current situation to the past. Risse does not deny the World Bank's grim figures on current poverty levels. However, he refuses to conclude that this in itself proves the 
global order to be unjust. Looking back in time, he reaches a more positive conclusion (Risse 2005b: 11-12):

what is remarkable is not that so many now live in poverty, but that so many do not; not that so many die young, but that so many do not; not that so many are illiterate, but that so many are not. By and large, if one looks at the last 200,100 , or 50 years, things have improved dramatically for the poor.

Risse (2005b: 12-15) acknowledges that this benchmark is not flawless. As Pogge rightly argues, we could after all be harming others although their situation has improved throughout history. ${ }^{10} \mathrm{~A}$ 'system' under which men beat the members of their family less than before cannot therefore be called just (Pogge 2008: 23). van der Veen faces the same objection, although his account is historical only in a weak sense. For example, if a certain, already existing, WTO-rule or treaty harms distant others and we fail to change it, are we really exonerated of harming those people because we are merely sustaining the status quo? Let us now consider whether the other two possible benchmarks could provide a way out.

As a second alternative, Risse mentions a counterfactual reference, namely comparing the current situation with a situation in which the global order did not develop as it did. How would the global poor fare if Africa had never been colonized? If they would be better off, the global economic order as we know it would in fact be harming them, according to this benchmark. This question, however, seems impossible to answer, as Risse correctly points out. Since there is only one world with one history, we have no meaningful point of comparison. Consequently, this benchmark cannot be invoked to challenge Pogge's claim (Pogge 2005b: 56). 
Risse's third alternative is a benchmark of fairness. Here the current order is compared to a 'state of nature' characterized by a fair distribution of resources. As the status quo is characterized by an uneven distribution and radical inequality, from the perspective of fairness the global economic order seems to harm the developing countries. However, according to Risse, this comparison can only show that the current distribution is not even, but not who is to blame for this. For example, it is not inconceivable that the unequal distribution is the result of a sequence of entirely voluntary transfers. ${ }^{11}$ Risse (2005b: 14) concludes:

the historical benchmark is the only benchmark among the three considered that we can make sense of, and in relation to that benchmark the global order has brought tremendous advances. Moreover, advances in medicine and food production are largely due to countries that have shaped that order. So, as far as we can tell, the global order has benefited the poor.

Even if we grant Risse that only the historical benchmark is workable, we need not embrace his optimistic outlook. Once we look past 'aggregates and averages' and focus on 'individual lives lived near the bottom' his account loses much of its force (Pogge 2005b: 5657). China and India have gone through a period of significant economic growth and the world's population has also increased. As a consequence, the percentage of global poor has indeed diminished. The fact however remains that, in absolute terms, the number of extremely poor people has increased since the beginning of the $19^{\text {th }}$ century (Chen \& Ravallion 2001: 290). Their suffering continues. Whether or not we are violating our negative duty not to harm distant others through upholding the global economic order thus seems to depend on the interpretation of the historical benchmark that we use. In relative terms, Risse may well be 
right to argue that the global poor have benefited from the global economic order. However, when we look at the absolute numbers, Pogge's claim is strengthened (Pogge 2008: 24). In Section 5 we will elaborate on a way to decide which interpretation of the historical benchmark we should favor. For now, we will conclude that upholding the global economic order can worsen the situation of distant others and can give rise to a special obligation of justice, depending on the benchmark one selects.

\subsection{Does climate change constitute a good reason to value relationships?}

Key to the argument sketched above is the condition of not actually worsening the situation of distant others when we sustain the status quo. In absolute terms, we have reason to believe that upholding the global economic order is harming distant others. When we focus on relative numbers, however, this conclusion is not self-evident. The question which we wish to raise now is which conclusion should be drawn when sustaining the status quo does worsen the situation of distant others beyond any reasonable doubt. We will address this question with reference to the case of climate change.

The adverse effects of climate change on human life include, inter alia, increased mortality (related to, for example, the increased frequency and magnitude of heatwaves), food and water insecurity, the spread and exacerbation of diseases, conflicts resulting from resource scarcity, and increased migration (Confalonieri et al. 2007; McMichael et al. 2008; Costello et al. 2009; McMichael \& Lindgren 2011). In this way, anthropogenic climate change jeopardizes the human rights to life, physical security, subsistence and health (Bell 2011: 100) for current and future people alike. In the climate case, doing nothing to improve the status 
quo thus indeed seems to worsen the situation of distant others and to violate their human rights.

Through our part in the process of climate change, we are violating the human rights of a specific and large subset of persons, hence we bear a special responsibility towards them. We are violating our negative obligation not to harm those distant others and we are under a binding obligation to transcend the increasingly harmful status quo. At the least, we bear the stringent obligation of justice to recompense those harmed and to implement the required reforms. Our responsibility in causing the harmful effects of climate change is beyond any reasonable doubt (IPCC 2013).

\section{The burden of proof}

Up to this point we have tried to establish whether or not we are harming people through the global economic order and climate change. We found that, concerning the economic order, the data are not entirely conclusive. On purely empirical grounds, the data used by Risse to defend his cause are as sound as those used by Pogge, given the complexity of the global economic system. So how should we proceed in this case? Concerning climate change, the harmful relation is more difficult to deny. However, grounding our special responsibilities on such an all or nothing mechanism seems incautious. The globalized context we live in is characterized by a multitude of causal connections and a diffusion of responsibilities, as Scheffler has pointed out (2001: 38-40). Demanding indisputable evidence of harm thus becomes a risky strategy, as these situations are seldom clear cut. In this way, we might be attaching too much importance to the demonstrability of harm. The danger exists that people 
are left to fend for themselves because they are unable to prove beyond any doubt that they are being harmed.

Christian Barry (2005a: 213-221) has attempted to address this problem by establishing fair standards of application for the so-called contribution principle, i.e. the principle that the obligations we bear are more weighty if we have contributed to a harmful situation. $\mathrm{He}$ distinguishes between three different standards of application. The first is the burden of proof, i.e. the question who has to provide the proof. The second is the standard of proof, i.e. the question how much proof is considered decisive. The third standard refers to the constraints on admissible evidence, i.e. the question what kinds of evidence will count as proof. The way these questions are answered can have a huge impact on the parties involved. Yet, as Barry concedes, there is no clear way of establishing whether these standards are fair. What counts as an appropriate standard depends on the context. In the context of a criminal trial, for example, the standards of application should be quite stringent to avoid punishing the innocent. Nonetheless, Barry (2005a: 216) rightly doubts whether we should extend such stringent standards to other areas of practical deliberation.

The degree of stringency of the standards, in Barry's view, may result in one of two errors. Either the accused is falsely believed to have contributed to the deprivations or harm (Type 1 error), or he is falsely believed not to have contributed (Type 2 error). The stringency we adopt depends on the importance we attach to avoiding either type of error (Barry 2005a: 216217). If we use extremely weak standards of application, some accused can be wrongfully convicted. If we use extremely strong standards, some accused can be wrongfully exculpated, and consequently some victims will remain uncompensated. So how can we determine the 
appropriate degree of stringency? Barry has formulated a special principle to help us make this choice in an ethical context, the 'vulnerability presumption principle' (2005a: 221):

Given the relative costs to [party A] and [party B] of Type 1 and Type 2 errors, I conclude that there is a strong prima facie case for specifying standards of application for applying the principle of contribution that expresses a willingness to err in favor of the acutely deprived subjects, whether they are the party alleging that they have been harmed or the party against which such claims have been made. I shall call this norm the "vulnerability presumption principle." While implausible as a principle for specifying standards of application in a criminal (and most likely in most civil) legal contexts, or as a principle for assessing ethical responsibilities more generally, the vulnerability presumption principle seems clearly superior to stringent standards of proof and evidence with respect to the determination of ethical responsibilities to address acute deprivations.

If we apply this principle to our argumentation so far, the need to be cautious becomes obvious. Regarding Pogge's claim that we are actively violating our negative duty not to harm distant others, we concluded that the validity of his claim will depend on which interpretation of the historical benchmark is used. Therefore, one could claim that we only bear duties of charity in delivering the positive human rights of distant others. We could say that we bear no special positive duties of justice ${ }^{12}$ towards them, as we (arguably) did not harm them, given the stringent standards of application that are normally used to establish harm. 
However, given the current situation, we would submit that Barry is right to argue for less stringent standards. Admittedly, his 'vulnerability presumption principle' quoted above cannot refute the libertarian argument that, relying on relative numbers, we owe the poor no positive duty of justice. Libertarians can choose to maintain stringent standards and so deny the legitimacy of special positive duties of justice, claiming that they do not harm anyone. However, in doing so, they would have to explain why they continue to use stringent standards for establishing harm. It seems reasonable to expect that their growing awareness of the demandingness of their own standards of application would pave the way for their accepting stronger positive duties of charity. A libertarian can maintain very high standards of application and thus deny that we are harming the global poor in upholding the global economic order. He can deny that we bear a positive obligation of justice to deliver on their human rights, since we did not violate their negative rights. However, in absolute terms, we are indeed harming distant others and there is no reason why we should prefer the relative numbers. To the contrary: "The killing of a given number of people does not become morally less troubling the more the world population increases. What matters morally is the number of people in extreme poverty" (Pogge 2005a: 92). Barry's vulnerability presumption principle raises further doubts about the legitimacy of focusing on relative numbers and, at least, makes a case for accepting stronger positive obligations of charity or assistance to deliver on human rights.

When we turn our attention to the second case discussed above, i.e., global climate change, Barry's principle seems to support a positive special obligation of justice. The evidence supporting the claim that we are harming distant others through climate change is stronger than it is for a similar claim regarding the global economic order. The former claim can thus withstand higher standards of application. Moreover, as climate change especially harms the 
global poor and thus the most vulnerable (World Bank 2013b), even a lower standard of evidence would suffice to establish a relationship of harm. For both these reasons, Barry's vulnerability presumption principle strengthens our argumentation: we do bear a positive special obligation of justice to remedy the situation of everyone affected by climate change.

\section{Concluding remarks}

Our framework for this paper was the responsibilities approach to human rights, focusing on the question 'who must do what for whom'? We distinguished between negative and positive human rights and the corresponding duties of noninterference and assistance. We then examined how these fit in with the common sense distinction between general and special obligations. We found that duties of noninterference seem to be valid for both general and special obligations, whereas duties of assistance are more controversial.

We examined whether this common sense view can be ethically justified and started our analysis with Scheffler's non-reductionist claim that positive special obligations are based upon relationships that one has reason to value, irrespective of whether or not these relationships are actually valued. The process of globalization has given rise to new reasons to value certain relationships and to bear new special responsibilities. We distinguished between obligations of charity and obligations of justice and we invoked the criterion of harm as the decisive benchmark.

Subsequently, we applied this framework to two cases: the global economic order and climate change. We argued that sustaining the global economic order can violate our negative duty not to harm others, but that this conclusion depends on the particular interpretation of the 
historical benchmark. Failing to mitigate climate change, in contrast, does entail a violation of our negative duties, for it actively causes harm and worsens the situation of distant others. Therefore, we have a reason to value our relationship with those who are adversely affected by climate change and we bear responsibility for them, even if we do not feel (sufficiently) motivated to assume such responsibility. The harm we cause through climate change thus grounds positive special obligations of justice to remedy this situation. Taking into account the harm we actually cause, gives rise to a special obligation to everyone who suffers because of that harm. As the adverse effects of climate change continue to exacerbate, we are getting ever closer to an account of global citizenship that implies fully global obligations.

By using harm as the criterion to solve the allocation problem (i.e. the question of who should deliver on human rights), we switched from a weak to a strong sense of human rights. If a relationship of harm is established, fulfilling positive duties is no longer a matter of general charity, but has become a special obligation of justice. Accordingly, human rights and corresponding obligations gain important normative weight.

Finally, we should like to note that using harm as the decisive benchmark requires caution, since whether or not something is considered a harm determines the status of the corresponding positive duties and, consequently, their normative force. Barry's 'vulnerability presumption principle' can play an important role in this regard. It strengthens our account of characterizing the positive duties of mitigating climate change as special obligations of justice. With respect to the global economic order, however, the vulnerability presumption principle could act as a tiebreaker. If we are considering whether to interpret the historical benchmark in relative or absolute numbers, Barry's principle could convince us to favor the most vulnerable. It urges us to concede that we are indeed violating our negative duties and 
that we therefore bear special obligations of justice. For those who still want to continue using the relative interpretation of the historical benchmark, Barry's vulnerability presumption principle should make them aware of the strict standards of application they use and the fact that this indicates their willingness to err at the expense of the global poor and the most vulnerable. At the least, Barry's principle seems to provide all of us with a strong reason to accept stronger positive obligations of charity or assistance to deliver on human rights.

\section{Notes}

${ }^{1}$ In art. 25(1) the UDHR explicitly formulates a right to an adequate standard of living, including food, clothing, housing, medical care and necessary social services.

${ }^{2}$ In Resolution 67/164, the UN General Assembly reaffirms that extreme poverty is a violation of human dignity and inhibits the observance of human rights. (UNGA 2012)

${ }^{3}$ On the characterization of poverty as a human rights violation, see Pogge (2008).

${ }^{4}$ Art. 26(1) UDHR

${ }^{5}$ We use the terms 'obligation' and 'duty' interchangeably.

${ }^{6} \mathrm{We}$ are not here presenting an exhaustive account of possible relationships, yet arguing that harm is a sufficient reason to value a relationship and generate responsibility.

${ }^{7}$ On the relation between moral judgment and motivation, see Rosati, "Moral Motivation", The Stanford Encyclopedia of Philosophy, 2006.

${ }^{8} \mathrm{http}$ ://healthimpactfund.org/next-steps

${ }^{9}$ Personal communication from Prof. Thomas Pogge.

${ }^{10} \mathrm{We}$ in no way deny that the global economic order, based on free trade, has improved the situation of the poor significantly. However, many human rights are being violated under the current regime and we believe a less harming alternative is feasible. To get a sense of what this alternative order might look like, see for example Collier (2007).

${ }^{11}$ If one favors historical principles over end-result principles, as Nozick (1974) does in his entitlement theory, an unequal distribution need not be unjust.

${ }^{12}$ On the issue of remedial responsibilities, see Miller 2001 \& 2007. This issue falls outside the scope of this article.

\section{References}

AUTY, Richard. (1993) Sustaining Development in Mineral Economies: The Resource Curse Thesis (London: Routledge).

BARRY, Christian. (2005a) Applying the Contribution Principle. Metaphilosophy, 36(1-2), $210-227$. 
BARRY, Christian. (2005b) Understanding and Evaluating the Contribution Principle. In Real World Justice, Andreas Follesdal and Thomas Pogge (eds.) (New York: Springer).

BARRY, Christian, and LAWFORD-SMITH, Holly (eds.). (2012) Global Justice (Farnham; Burlington, VT: Ashgate).

BELL, Derek. (2011) Does Anthropogenic Climate Change Violate Human Rights? Critical Review of International Social and Political Philosophy, 14(2), 99-124.

CANEY, Simon. (2010) Climate Change, Human Rights, and Moral Thresholds. In Climate Ethics: Essential Readings, Stephen M. Gardiner, Simon Caney, Dale Jamieson and Henry Shue (eds.) (Oxford and New York: Oxford University Press).

CHEN, Shaohua, and RAVALLION, Martin. (2001) How did the world's poorest fare in the 1990s? Review of Income and Wealth, 47, 283-300.

COLLIER, Paul. (2007) The Bottom Billion. Why the Poorest Countries Are Failing and What Can Be Done About It (New York: Oxford University Press)

CONFALONIERI, Ulisses, MENNE, Bettina, AKHTAR, Rais, EBI, Kristie L., HAUENGUE, Maria, KOVATS, Sari, REVICH, Boris, and WOODWARD, Alistair. (2007) Human Health. In Climate Change 2007: Impacts, Adaptation and Vulnerability. Contribution of Working Group II to the Fourth Assessment Report of the Intergovernmental Panel on Climate Change, Martin L. Parry, Osvaldo F. Canziani, Jean P. Palutikof, Paul J. van der Linden, and Clair E. Hanson (eds.), 391-431. (Cambridge: Cambridge University Press). [Online]. Available: http://www.ipcc.ch/pdf/assessment-report/ar4/wg2/ar4-wg2chapter8.pdf [2 May 2013].

COSTELLO, Anthony, ABBAS, Mustafa, ALLEN, Adriana, BALL, Sarah, BELL, Sarah, BELLAMY, Richard, FRIEL, Sharon, GROCE, Nora, JOHNSON, Anne, KETT, Maria, LEE 
CAREN LEVY, Maria, MASLIN, Mark, McCOY, David, McGUIRE, Bill, MONTGOMERY, Hugh, NAPIER, David, PAGEL, Christina, PATEL, Jinesh, ANTONIO PUPPIM de OLIVEIRA, Jose, REDCLIFT, Nanneke, REES, Hannah, ROGGER, Daniel, SCOTT, Joanne, STEPHENSON, Judith, TWIGG, John, WOLFF, Jonathan, and PATTERSON, Craig. (2009) Managing the health effects of climate change. The Lancet, 373, 1693-1733.

CRUFT, Rowan. (2005) Human Rights and Positive Duties. Ethics and International Affairs, 19(1), 29-37.

DOBSON, Andrew. (2003) Citizenship and the Environment (Oxford: Oxford University Press).

EVANS, Peter. (2005) The Challenges of the Institutional Turn: New Interdisciplinary Opportunities in Development Theory. In The Economic Sociology of Capitalism, Victor Nee and Richard Swedberg (eds.) (Princeton, N.J.: Princeton University Press).

FOOD and AGRICULTURE ORGANIZATION. (2013) Statistical Yearbook. [Online]. Available: http://www.fao.org/docrep/018/i3107e/i3107e02.pdf [20 December 2013].

GOODIN, Robert. (1985) Protecting the Vulnerable (Chicago: University of Chicago Press).

HARDIMON, Michael. (1994) Role Obligations. Journal of Philosophy, 91(7), 333-363.

HAYWARD, Tim. (2008) On the Nature of Our Debt to the Global Poor. Journal of Social Philosophy, 39(1), 1-19.

HINSCH, Wilfried, and STEPANIANS, Markus. (2005) Severe Poverty as a Human Rights Violation - Weak and Strong. In Real World Justice, Andreas Follesdal and Thomas Pogge (eds.) (New York: Springer). 
HOLLIS, Aidan, and POGGE, Thomas. (2008) The Health Impact Fund: Making Medicines Available for All (New Haven, CT: Incentives for Global Health).

HOORNWEG, Daniel, SUGAR, Lorraine, FREIRE, Mila, ANDERSON, Christa, BHADA, Perinaz, TREJOS, Claudia L., DAVE, Rutu, and LEE, Marcus. (2010) Cities and Climate Change: An Urgent Agenda. (Washington, DC, USA: World Bank). [Online]. Available: http://siteresources.worldbank.org/INTUWM/Resources/3402321205330656272/CitiesandClimateChange.pdf [17 June 2013].

INTERGOVERNMENTAL PANEL on CLIMATE CHANGE. (2013) Climate Change 2013. The Physical Science Basis. [Online]. Available: http://www.climatechange2013.org/images/uploads/WGIAR5_WGI12Doc2b_FinalDraft_All.pdf [10 January 2014].

KUPER, Andrew. (2002) More Than Charity: Cosmopolitan Alternatives to the "Singer Solution”. Ethics and International Affairs, 16(1), 107-128.

KUPER, Andrew (ed.). (2005) Global Responsibilities: Who Must Deliver on Human Rights? (New York: Routledge).

LINKLATER, Andrew. (1998) The Transformation of Political Community: Ethical Foundations of the Post-Westphalian Era (Cambridge: Polity).

McMICHAEL, Anthony J., NYONG, Anthony, and CORVALAN, Carlos. (2008) Global environmental change and health: impacts, inequalities, and the health sector. $B M J, 336,191-$ 194.

McMICHAEL, Anthony J., and LINDGREN, Elisabet. (2011) Climate change: Present and future risks to health, and necessary responses. Journal of Internal Medicine, 270(5), 401-413. 
MILLER, David. (2001) Distributing responsibilities. The Journal of Political Philosophy, 9(4), 453-471.

MILLER, David. (2005) Reasonable Partiality towards Compatriots. Ethical Theory and Moral Practice, 8, 63-81.

MILLER, David. (2007) National Responsibility and Global Justice (New York: Oxford University Press).

MOELLENDORF, Darrel. (2002) Cosmopolitan Justice (Boulder (Colo.): Westview Press).

NAGEL, Thomas. (1972) War and Massacre. Philosophy \& Public Affairs, 1(2), 123-144.

NAGEL, Thomas. (2005) The Problem of Global Justice. Philosophy \& Public Affairs, 33(2), $113-147$.

NARVESON, Jan. (1988) The Libertarian Idea (Philadelphia: Temple University Press).

NOZICK, Robert. (1974) Anarchy, State, and Utopia (New York: Basic Books).

PATTEN, Allan. (2005) Should We Stop Thinking about Poverty in Terms of Helping the Poor? Ethics and International Affairs, 19(1), 19-27.

POGGE, Thomas. (1992) Cosmopolitanism and Sovereignty. Ethics, 103, 48-75

POGGE, Thomas. (2001) Priorities of Global Justice. Metaphilosophy, 32(1-2), 6-24.

POGGE, Thomas. (2005a) A Cosmopolitan Perspective on the Global Economic Order. In The Political Philosophy of Cosmopolitanism, Gillian Brock and Harry Brighouse (eds.) (Cambridge: Cambridge University Press).

POGGE, Thomas. (2005b) Severe Poverty as a Violation of Negative Duties. Ethics and International Affairs, 19(1), 55-83. 
POGGE, Thomas. (2008) World Poverty and Human Rights: Cosmopolitan Responsibilities and Reforms (Cambridge: Polity, Second Edition; First Published in 2002).

RAWLS, John. (1999) The law of peoples with The idea of public reason revisited (Cambridge: Harvard University Press).

RISSE, Mathias. (2005a) How Does the Global Order Harm the Poor? Philosophy \& Public Affairs, 33(4), 349-376.

RISSE, Mathias. (2005b) Do We Owe the Global Poor Assistance or Rectification? Ethics \& International Affairs, 19(1), 9-18.

ROSATI, Connie S. (2006) Moral Motivation. The Stanford Encyclopedia of Philosophy, Edward N. Zalta (ed.). [Online]. Available:

http://plato.stanford.edu/archives/win2006/entries/moral-motivation [10 December 2013].

SCHEFFLER, Samuel. (1995) Individual Responsibility in a Global Age. Social Philosophy and Policy, 12, 219-236.

SCHEFFLER, Samuel. (2001) Boundaries and allegiances. Problems of justice and responsibility in liberal thought (Oxford: Oxford University Press).

SHUE, Henry. (1980) Basic Rights (Princeton: Princeton University Press).

UNITED NATIONS. (2012) MDG Gap Task Force Report. [Online]. Available: http://www.un.org/millenniumgoals/2012_Gap_Report/MDG_2012Gap_Task_Force_report.p df [10 January 2014].

UNITED NATIONS. (2013) The Millennium Development Goals Report. [Online]. Available: http://www.un.org/millenniumgoals/pdf/report-2013/mdg-report-2013-english.pdf [10 January 2014]. 
UNITED NATIONS GENERAL ASSEMBLY. (1948) A Universal Declaration of Human Rights (A/RES/217>(III)). [Online]. Available:

http://www.un.org/Docs/asp/ws.asp?m=A/RES/217\%20\%28III\%29 [29 January 2014]

UNITED NATIONS GENERAL ASSEMBLY. (2012) Human rights and extreme poverty (A/RES/67/164). [Online]. Available:

http://www.un.org/en/ga/search/view_doc.asp?symbol=A/RES/67/164 [29 January 2014]

VAN DER VEEN, Robert. (2005) Hebben de rijke landen een negatieve plicht om de armoede in de wereld te bestrijden? In Internationale Rechtvaardigheid. Over Politiek en Ethiek in een Mondiaal Tijdperk, Gert Verschraegen and Ronald Tinnevelt (eds.) (Kapellen: Pelckmans).

VAN DER VOSSEN, Bas. (2011) Associative Political Obligations: Their Potential.

Philosophy Compass, 6(7), 488-496.

WELLMAN, Christopher. (2000) Relational Facts in Liberal Political Theory: Is There Magic in the Pronoun 'My'? Ethics, 110(3), 537-562.

WORLD HEALTH ORGANIZATION. (2013) Diarrhoeal disease. [Online]. Available: http://www.who.int/mediacentre/factsheets/fs330/en/ [20 December 2013]

WILLIAMS, Bernard. (1981) Moral Luck: Philosophical Papers, 1973-80 (Cambridge: Cambridge University Press).

WORLD BANK. (2013a) Poverty. [Online]. Available:

http://www.worldbank.org/en/topic/poverty/overview [20 December 2013].

WORLD BANK. (2013b) What Climate Change Means for Africa, Asia and the Coastal Poor. [Online]. Available: http://www.worldbank.org/en/news/feature/2013/06/19/whatclimate-change-means-africa-asia-coastal-poor [20 December 2013]. 
YPI, Lea, GOODIN, Robert, and BARRY, Christian. (2009) Associative Duties, Global Justice, and the Colonies. Philosophy and Public Affairs, 37, 103-135. 